\title{
STUDY THE NEED OF BASELINE ENERGY USE BENCH MARKING OF BUILDINGS IN DIFFERENT CLIMATE ZONES OF INDIA
}

\author{
Mr. Kishan Khatri ${ }^{1}$ Dr. Shweta Choudhary ${ }^{2}$ \\ ${ }^{1}$ PG Student (Sustainable Design), Vivekananda Global University \\ ${ }^{2}$ Dean (Centre Head CODE), Vivekananda Global University
}

Article DOI: https://doi.org/10.36713/epra7416 DOI No: 10.36713/epra7416

\begin{abstract}
-
The aim of research is to identify a need of a baseline energy use for benchmarking the minimum energy performance of the buildings for different climate zones of India. Its objective is to provide information and create awareness among customers on energy performance so that consumers can make informed decisions while purchasing appliances, selecting the ECMs and in creating a sustainable home. This study will help in the identification of underperforming buildings to target for efficiency improvements, identify best practices from efficient buildings, set investment priorities, verify savings and prevent snapback, share and report performance, earn recognition, continuous monitoring and implement a comprehensive management program. There are rating system available in India i.e. BEE Star Labelling program and GRIHA Baseline Energy Use to support these requirements. However, there are some limitation in the terms of Climate Zones and Standardization. The baseline energy use differs with each other on a certain parameter, which can create a misinterpretation for the building owners to rely on any standard. There is a need of knowing the current status/performance of the building as comparison to the similar type of buildings in India in respective climate zones. There is a further need to getting recognized by the authority at national level providing the status of the building energy performance. Enormous studies have been made and have suggested to follow the best Energy Conservation Measures (ECM's) in the buildings. However, there is no portal or tool which can guide what further energy performance is needed to choose the ECMs accordingly. There is an online portal called Energy Star Portfolio Manager in USA which looks closer to the need and for the same a research has been carried out including all the stakeholders, engineers, architects, consultants to come up with the need of online benchmarking tool, accessible for all the building holders. Further, the expertise of BEE Certified Energy Auditors and Energy Managers can be helpful in the identification of this eco system of energy use benchmarking for the different climate zones of India.
\end{abstract}

KEYWORDS: Energy Use; Green Buildings; Climate Zones; Energy Performance Benchmarking; Energy Star Portfolio Manager-

\section{INTRODUCTION}

This document introduces with study the need \& importance of Baseline Energy Use Benchmarking of Buildings in different Climate Zones of India.

As a part of growing movement toward sustainable world, India has been playing its role by forming different regulation bodies related to green buildings and sustainability. Some of such organisation are IGBC (Indian Green Building Council), GEM (Green and Eco-Friendly Movement), GRIHA (Green Rating for Integrated Habitat Assessment), BEE (Bureau of Energy Efficiency), etc. Among these, BEE and GRIHA has formulated the energy benchmarking separately. Energy Benchmarking can help in the following ways: 
1. Establishing baseline energy requirement for a building/process /activity.

2. Benchmarking provides data for comparison with similar firms / businesses. The comparison helps in identifying gaps, areas of improvements especially the big-ticket items.

3. Helps firms remain within the stipulated guidelines in terms of energy usage, be more environmentally conscious.

4. Knowledge of energy patterns helps firms make huge cost saves by taking advantage of reducing max demand, scheduling of equipment/activities to reduce load during peak hours, optimise chiller \& AHU set points, etc.

5. Ease of utility budget forecast.

6. Building energy consumption data helps cities strategically meet energy efficiency goals and climate change reduction goals.

7. Provides a competitive edge.

8. Helps develop accurate strategic plans with regards to utility consumption and eases expansion projects.

9.

Bureau of Energy Efficiency, Ministry of Power, Government of India (BEE) is the first body formed in India in objective of setting minimum energy efficiency standards for design and construction of new commercial buildings. ECBC was introduced in 2007, that was design guide. Further, the energy use benchmarking or performance rating was introduced in 2009 named as "BEE Star Labelling for commercial buildings" for offices and IT buildings for three climate zones of India. This rating programme is being given to commercial buildings on the basis of energy performance. Energy Performance Index (EPI) in $\mathrm{kWh} / \mathrm{m} 2 / \mathrm{year}$ is used as the key performance indicator. Energy Performance Index (EPI) of a building is based on entirely based on energy consumption of the project including consumption from utility or grid as well as energy generated onsite via Diesel generators sets or Solar PV installed at site. The buildings are rated on the scale of from 1 to 5 star with the 5-star label buildings being the most efficient. The program targets generally IT buildings $\&$ office. Till date, around 108 office buildings and 17 IT buildings have been enrolled \& awarded with BEE star rating performance label.
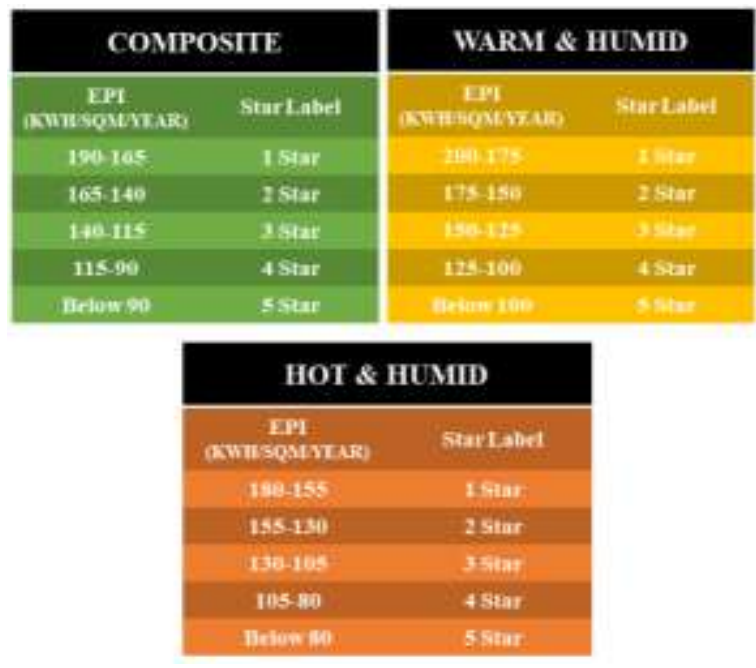

Figure 2 BEE rating for office building whose conditioned area is greater than $50 \%$ of built-up area
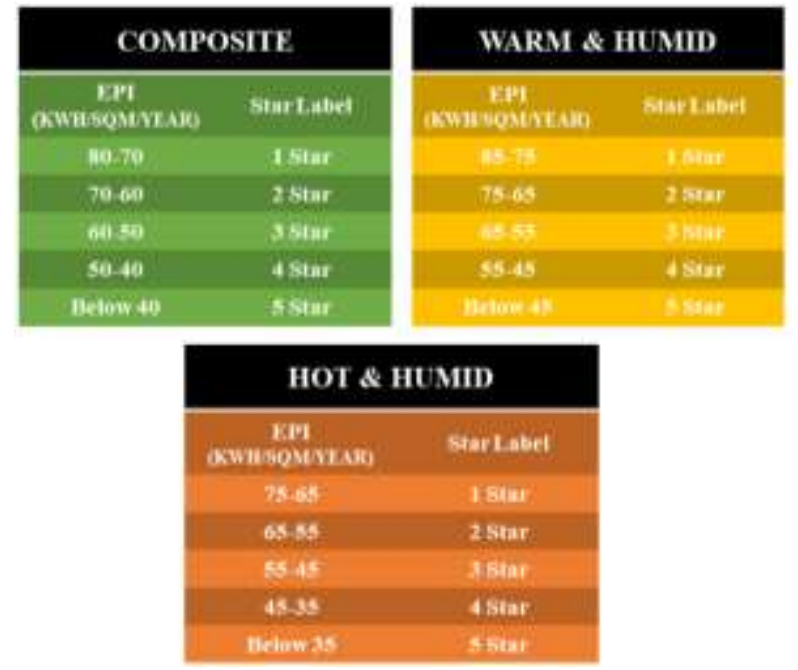

Figure 1 BEE rating for office building whose conditioned area is smaller than $50 \%$ of built-up area

Additionally, GRIHA has also introduced the baseline energy use benchmarking for four climate zones of India. The better the performance is more the points are awarded in GRIHA Rating in Energy Efficiency Criteria. The rating is for both commercial and residential, unlike the BEE which is for commercial only. GRIHA's method of evaluation for green building certification is different compared to other standards. They 
rate buildings performance by doing life cycle approach over its entire entities, this includes the energy performance as well.

\begin{tabular}{|c|c|c|}
\hline \multicolumn{2}{|c|}{ Energy Performance Index (EPI) for buildings } \\
\hline \multirow{2}{*}{ Climate Classification } & \multicolumn{2}{|c|}{ EPI $\left(\mathrm{kWh} / \mathrm{m}^{2} /\right.$ Year) } \\
\cline { 2 - 3 } & Day Time Occupancy & 24 hours Occupancy \\
\hline Commercial/Institutional Buildings & $\mathbf{8}$ Hours 5 Days & $\mathbf{2 4}$ Hours 7 Days \\
\hline Moderate & 120 & 350 \\
\hline Composite/Warm \& humid/Hot \& Dry & 140 & 450 \\
\hline Residential Buildings & \multicolumn{2}{|c|}{ EPI $\left(\mathbf{k W h} / \mathbf{m}^{2} /\right.$ Year $)$} \\
\hline Composite/ warm and humid/ hot and dry & \multicolumn{2}{|c|}{100} \\
\hline Moderate & \multicolumn{2}{|c}{85} \\
\hline
\end{tabular}

In other country like USA, there is a common energy use benchmarking named Energy Star Portfolio Manager to rate the buildings energy performance. The ENERGY STAR score compares the building's energy performance to similar buildings nationwide, normalized for weather and operating characteristics. The performance is measured on the scale of 1 to 100 and through the Energy Use Intensity (EUI). A higher score of Energy Star is better and lower is worse. Similarly, Higher the Energy Star Score, lower the EUI.
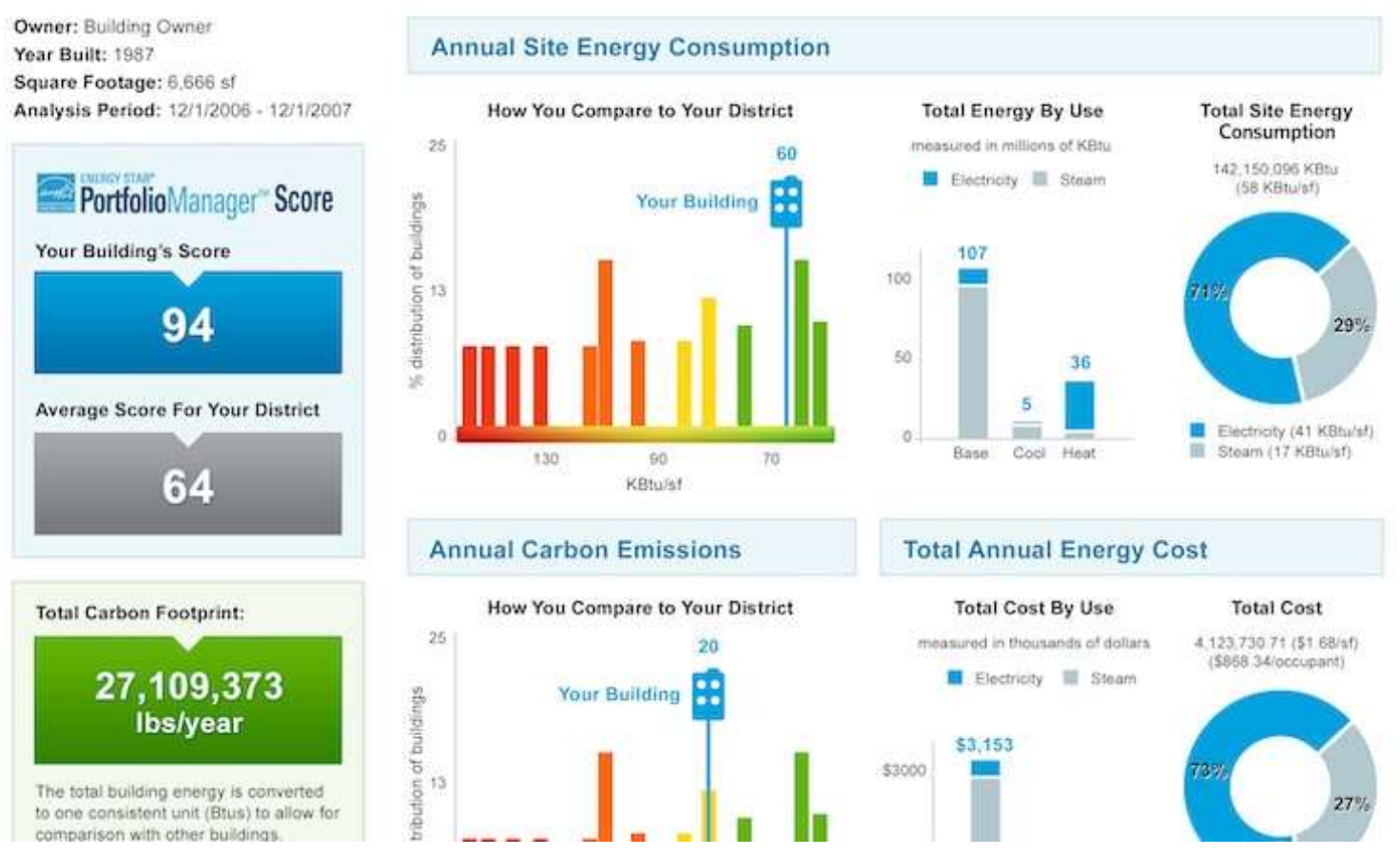

Figure 3 Energy Star Portfolio Manager Portal

The inputs which are considered for checking the energy use are:

Connected Load $(\mathrm{kW})$, installed capacity of DG sets (kVA or kW), total annual electricity consumption, HSD consumption, Natural Gas consumption, Solar PV generation, Area of the building, working hours ( $8 \mathrm{hr} /$ $24 \mathrm{hr}$ ), working days per week (5/6/7 days per week), total no of employees working, and average no of employees present at any time in building, number of computers, number of refrigerators, air-conditioned area, parking area, location of the building, installed lighting load $(\mathrm{kW})$, etc.

\section{RESEARCH BACKGROUND}

Various types of studies are being conducted to create a reference baseline building model. Recent times, lots of importance is given for implementing ECM's in buildings. However, the implementation is not straight 
forward for all buildings in all climatic zones as there are several dissimilarities in terms of their façade properties, climatic conditions, inner load gains and loss, operating schedules etc. Hence, ECM and benchmarking regulations stridently be formed for various factors rather than a selected few factors.

Europe's EPBD (European Performance Building Directive) has developed baseline reference building and defined it as a "buildings characterized by and representative of their functionality and geographic location, including indoor and outdoor climate conditions". 16 reference buildings models representing $70 \%$ of national building stock of the US has been developed by the U.S.DOE (Department of Energy) [2]. From [3], European Union Journal has established "Cost-optimal methodology framework" which describes about the framing of reference buildings, identifications of ECM's and the evaluation of its corresponding energy consumption values with respect to ECM measures. They have further undertaken a evaluation of energy performance of each reference building in terms of cost and also estimated the NPV [Net present value].

Another research by Lam J.C. et.al. [4] has derived an equation for calculating energy consumption of 12 key building design parameters. His base case building was designed with 5 square zones and having 40 floors. This building is then categorised based on three factors: building load, HVAC system and HVAC plant. Another study from K.S.Y Want et al. [5], has established baseline building model for residential type buildings with internal load pattern, HVAC and other parameter operation schedules through a survey. His intention was to use the developed reference building to benchmark the energy performance of the envelope actual existing residential buildings.

Another method employed in establishing baseline building is through simulation model. The study by L.M. Halburd et al [6] created baseline building through simulation representing a real time UK office building. The parameters prioritized by him are built form, construction elements and occupancy. Furthermore, he has developed operational strategy. His reference building can be used to analyse the energy performance of the building stocks and also can be used for retrofitting strategies.

For more accurate modelling of the dynamical parameters related to buildings stocks, Famuyiba et al. [7], employed multi linear regression analysis, clustering and descriptive statistics method for representation of the variability of overall building stocks in terms of geometric form, constructional materials and operation. Based on existing information about housing details. By this, the study was able to create 13 representative archetypes. Reference building for Portugal and Brazil were defined by cluster analysis [8, 9]. Journal by Evans et al[cite15] proposed a procedure to attach the database of information to $3 \mathrm{D}$ mapping sources. This $3 \mathrm{D}$ model can be simulated with real time data about geometry and construction.

For different regions across globe, lots of studies had been undertaken. For India, we too have overly complex climatic conditions. We have 5 different climatic conditions and along with it, the schedules of different parameters vary among different regions, based on building types and activities. So, establishing a baseline model for India becomes more complex and required in-depth research.

The study by Devgan et al. reported the formulation of Overall Heat Transfer Value (OTTV) coefficient for different climate zones in India. The shape of the building considered was Octagonal in-order to represent 8 orientations. For the analysis and verification of existing ECBC codes, 16 building prototypes were made. The base used for in creating 2007 code is very much different form 2016 code. The building consisted of square model with 5 zones comprising of 4 perimeters and 1 core.

Another study (Bhatnagar et al.) highlighted that a standard baseline reference building of corresponding building type has not been yet identified. The standards in India are still using the square shaped 5 zone building types for the corresponding energy analysis and formation of policies. The study further highlighted that the absence of standard reference buildings, different research groups are considering different building typologies while conducting analysis for policy formations which in turn result in different outcomes even for similar inputs.

Due to these differences, ECM's implemented in buildings in India becomes either partially or fully ineffective, therefore leaving the owner with confusion and loss of money he invested for ECMs. On other hand, this in turn demotivates people to follow ECM and reduce the awareness for Energy conservation in India. In order to avoid such negative effects, we also try to undertake a research to find out the need for the establishment of standard baseline reference building. The study further created reference building of office building for India for evaluation of energy performance of both reference building and building with ECBC code. Their methodology is based on the steps as:

Identification of Building Typologies - Identification of building parameters - Calculation of building size and data collection-determining values of building parameters.

An office reference building was developed for two different categories based on their respective operating hours. Some are categorised under $8 \mathrm{hr}$ operation and some are under $24 / 7 \mathrm{hr}$ operation. From his research he has developed the reference office buildings for India. He employed statistical analysis for 
categorical and numerical variables of a building. Bin Method was used to evaluate the data. He found that EPI of ECBC 2017 base model is as efficient as his model. The reason attributed is the generated baseline model parametric values are more efficient than ECBC 2017. ECBC's LPD (Light power density is found to be lower) than the simulated. Furthermore, it is found that chiller COP of high-rise reference building, envelope properties are slightly inefficient than ECBC 2017.

He found that the controls employed in reference building are less common. Therefore, even with efficient systems, if there are no appropriate controls, they will not provide sustainable savings. He found that the parametric values are not showing significant variations according to different climatic zones. He finally concluded that that there should be a review of reference building in almost every 5 years and there should a centralized zone or method for collection of data with respect to building. He also stated the research on creating standard baseline should be continued often to create a proper reference building and there by improved energy efficient standards. This allows us to further research on this topic and we can wide the scope to residential and other building types as well including office.

\section{METHODOLOGY}

The methodology of the research shall include the surveys. The step by step process has been provided below:

1. To select best suitable sampling method.

2. To identify the surveyors who shall participate in the research and shall share the feedback.

3. Questionnaire to be prepared related to the research and the subject.

4. Collection of data/feedback through Microsoft Online Form.

5. Analysis of the fetched data.

6. Conclusion and decision of the need of online portal for energy use benchmarking

7. Identification of the role of Energy Auditors and Energy Managers for approving the data authenticity in getting the recognition for best energy performing buildings.

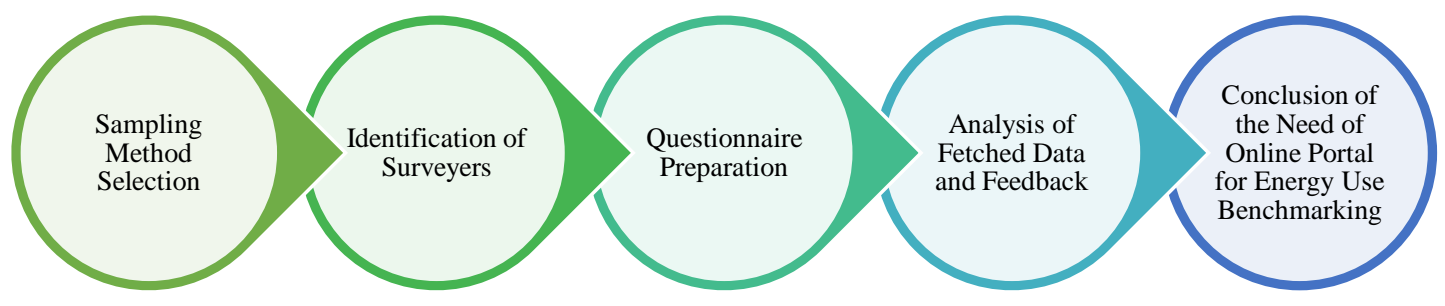

\section{CONCLUSION}

By comparing both GRIHA's EPI performance Index and BEE EPI performance Index used for building labelling's, it is clearly visible that the EPI index values are totally different. For Example, In GRIHA, EPI values for buildings in Composite, warm and humid, hot and dry are same while in BEE, EPI values are totally different. Now, how we can arrive at the conclusive evidence of the corresponding energy performance of the building when you have two different measuring indexes. This difference will demotivate customers from opting energy efficient ECM's in their buildings. These issues will surely reduce the demand for energy efficient buildings and force people to priorities the initial cost rather than operating cost of the building.

In ECBC 2017, EPI ratio has been defined rather than EPI benchmark value. EPI ratio is defined as ratio of Proposed EPI to the ratio of Baseline EPI. Here, Baseline EPI is based on standard values given in ECBC and may change case to case basis. The concept of energy use benchmarking shall be applied in the building labelling tool, and such kind of tool shall be more unanimously belongs to one body where Energy Performance of all types of building across different regions under different climate zones could avail the tool and estimate their house hold energy consumption and performance. Further, this single tool can even be used to select the suggestions on possible ECM's to the customer to convert either their existing or future building to energy efficient ones according to the set targets. Thereby creating a uniform Energy Performance analyzer tool will increase the demand for sustainable buildings among customers across India. The expertise of Energy Managers and Energy Auditors from BEE can be very helpful in the complete eco system of the energy monitoring and efficiency. 
1. Bhatnagar et al., Development of reference building models for India. Jaipur 21(2019) 267-277.

2. M. Deru, K. Field, D. Studer, K. Benne, B. Griffith, P. Torcellini, B. Liu, M. Halverson, D. Winiarski, M. Rosenberg, M. Deru, K. Field, D. Studer, U.S. Department of Energy Commercial Reference Building Models of the National Building Stock U.S. Department of Energy Commercial Reference Building Models of the National Building Stock, 2011.

3. Directive 2010/31/EU on the energy performance of buildings (recast) - 19 May 2010 | Build Up. [Online]. Available: /http://www.buildup.eu/en/practices/ publications/directive-201031eu-energy-performance-buildingsrecast-19-may-2010). (Accessed 05 June 2018).

4. J.C. Lam, K.K.W. Wan, D. Liu, C.L. Tsang, Multiple regression models for energy use in air-conditioned office buildings in different climates, Energy Convers. Manag. 51 (12) (. 2010) 2692-2697

5. K.S.Y. Wan, F.H.W. Yik, Representative building design and internal load patterns for modelling energy use in residential buildings in Hong Kong, Appl. Energy 77 (1) (2004) 69-85.

6. I. Korolija, L. Marjanovic-Halburd, Y. Zhang, V.I. Hanby, UK office buildings archetypal model as methodological approach in development of regression models for predicting building energy consumption from heating and cooling demands, Energy Build. 60 (2013) 152-162

7. A.A. Famuyibo, A. Duffy, P. Strachan, Developing archetypes for domestic dwellings an Irish case study, Energy Build. 50 (2012) 150-157

8. A. Brandão de Vasconcelos, M.D. Pinheiro, A. Manso, A. Cabaço, A Portuguese approach to define reference buildings for cost-optimal methodologies, Appl. Energy 140 (2015) 316-328

9. A. Schaefer, E. Ghisi, Method for obtaining reference buildings, Energy Build. 128 (2016) 660-672

10. S. Evans, R. Liddiard, P. Steadman, A 3D geometrical model of the non-domestic building stock of England and Wales, Build. Simul. Optim. (2014) 